\title{
Carbon Emission and Optimization of Energy for Sustainable Development: Rethinking the Possibility
}

\author{
Samuel Sunday Idowu ${ }^{1 *}$, Siti Indati Mustapa ${ }^{2}$ and Segun Joshua ${ }^{3}$ \\ ${ }^{1}$ Department of Political Science and International Relations, Covenant University, Ota, Nigeria, ${ }^{2}$ Institute of Energy Policy and \\ Research Jalan IKRAM-UNITEN, Kajang Selangor, Malaysia, ${ }^{3}$ Kola Daisi University, Ibadan, Nigeria
}

OPEN ACCESS

Edited by:

Samuel Asumadu Sarkodie,

Nord University, Norway

Reviewed by:

Andrew Alola,

Istanbul University, Turkey

Seyi Akadiri,

Eastern Mediterranean University,

Turkey

*Correspondence:

Samuel Sunday Idowu

sunsamd@yahoo.com

Specialty section:

This article was submitted to

Advanced Clean Fuel Technologies,

a section of the journal

Frontiers in Energy Research

Received: 07 August 2020

Accepted: 19 October 2020

Published: 11 January 2021

Citation:

Idowu SS, Mustapa SI and Joshua S (2021) Carbon Emission and

Optimization of Energy for Sustainable

Development: Rethinking

the Possibility.

Front. Energy Res. 8:592506.

doi: 10.3389/fenrg.2020.592506
The adverse effects of climatic change and environmental degradation associated with the fossil energy sources from crude oil, coal, and gas have been used as a sad commentary by some transnational organizations and multilateral concern. Thus, such campaigns, actions, and concerted efforts are geared towards making them redundant while canvassing for renewable energy sources as perfect alternatives. Although gas is characterized by lower carbon emission, it is somehow not considered as a source capable of being improved upon for a sustainable energy source. Hence, this research is undertaken to project the viability of gas energy with a minimum deleterious impact on nature and humanity. With secondary data sources, the study employed a descriptive research method and employed dynamic capabilities theory as a framework. It was discovered through the study that state politicking that surrounds the current moves to jettison the fossil energy, and the multilateral concern also backs the ploy towards its abandonment, resulting in the development of cold feet towards renewing interests in engaging science, technology, and innovation to further decarbonize the gas energy. The authors suggest, among others, the need for a deliberate engagement of a cutting-edge research and innovative technology through collaborations among countries and international organizations such as OPEC and oil firms. If this is done, it will enhance its relevance even without compromising the minimum biosafety and environmental standards.

Keywords: carbon emission, energy, gas, sustainable development, dynamic capabilities

\section{INTRODUCTION}

The importance of energy to a country's social, industrial, and overall economic development has been unanimously acknowledged by scholars and investors across disciplines and hence cannot be overemphasized. However, while there are multiple sources of energy broadly categorized as nonrenewable fossil fuel, such as oil, coal, and gas, and renewable (wind, hydro, and solar), the division also largely determine their sustainability acceptability as an enduring or reliable source by the global community. This is predicated on the aftereffects of the nonrenewable energy consumption on the ecosystem, especially the warming of the ozone layers resulting from the acidic emissions. For instance, Muhammad et al. (2019) found that an increase in coal and gas energy consumption boosted the $\mathrm{CO}_{2}$ emission in Pakistan, typifying what is obtainable in many of the emerging and developing economies characterized by high usage of nonrenewable fuel and, perhaps, the industrialized economies with penchant for fossil fuel as well. 
Moreover, the current pieces of evidence of the negative impact on the weather, altering its natural cycle with seismic spillover in the form of increasing the global temperature (global warming), disturbance of the aquatic environment, and other natural life disruptions, have also raised concerns and heighten campaigns and efforts to rescue the situation. For example, the planetary warming record in 2016 was 1.1 degree centigrade higher than the preindustrial period, while the global sea that fell into 4.14 million, the second lowest record same year, informed the basis for the Paris Agreement in 2016 to tackle the goal 13 of the sustainable development goals (SDG), which is to take drastic action in combating climate change and its impact with more likelihood of making the natural resources stranded (United Nations (UN), 2017). Also, the Parish Agreement is not just for advancing an alternative energy source but also promoting it for global development (Zheng-Xia et al., 2018). By implication, renewable energy tends to be rapidly becoming the toast of the global market, while the threat of stranding the fossil fuel is making countries housing and currently leveraging on these resources for their social, economic, or material development apprehensive as their fate seems to hang in the balance.

However, the continuous search for crude oil by countries with the potentialities and according to Ike et al. (2020) assertion that the United States and Canada sand and shale oil boom have renewed their dependence on fossil energy and might not be in their best economic interest to jettison, it appears to underscore the current relevance of nonrenewable energy despite the intensified campaign aimed to dampen it. Additionally, one of the findings of Ike et al. (2020) revealed that the trade spurred $\mathrm{CO}_{2}$ emission, and Bekun et al. (2019) revealed that the pursuit of economic growth by countries that influence carbon emission is instructive of the essentiality of energy, generally, to every country's economy survival and the need to mitigate its adverse effects. This, as well, suggests the central position the fossil energy still occupies in powering both the domestic and the international transportation systems aside from increasing the traffic of commercial activities across borders.

Meanwhile, fossil fuel is generally identified as the main contributor to the disturbing climatic condition, environmental degradation, air pollution, carbon dioxide emission $\left(\mathrm{CO}_{2}\right)$, and methane. And the adverse effects of climatic change and environmental degradation associated with the fossil energy sources have been used as a sad commentary by some transnational organizations and multilateral concern. This is often analyzed with a little regard to variation in the degree of emission of the nonrenewable energy sources. For instance, gas is argued to possess the least $\mathrm{CO}_{2}$ among the fossil fuel energy sources with an inherent capacity for further reduction (Alberto, 2018). But it appears that the adaptability of gas energy to the current global drive towards a minimal $\mathrm{CO}_{2}$ economic development trajectory is either considered improbable, excluded, or downplayed by multilateral organizations, and states more prone to hazards of climate change (such as a small island or coast territories) often champion an expeditious implementation of the Paris Agreement because of gas associated with the nonrenewable energy class. The question that naturally arises from this is can clean energy still be gleaned from gas? Or put differently, is it possible to improve on gas fuel decarbonization to an acceptable level in the energy market? Given this prevailing situation, therefore, this article has as its overall objective to ferret out the possible means through which gas can make a significant contribution to the contemporary clean energy pursuit, especially in the transitioning period without undermining the global environmental protection goal.

\section{LITERATURE REVIEW}

Some research studies on decarbonization of fossil fuel, especially on gas, have been done by scholars. This section examines some of the recent empirical findings in the literature intending to interrogate their submissions and other related issues. First, in the research conducted by the US Department of energy-Quadrennial Technology Review (QTR) (2015) titled "Oil and Gas Technology: Subsurface Science, Technology and Engineering," it posits from the review of secondary data that the oil and gas have transformed through research and development (R\&D) and technology to lower their carbon emissions level for a sustainable usage and to mitigate its adverse effects on the environment, human, and aqua biodiversity. However, while efforts and resources have been deployed by the US government, researchers, and practitioners to improve the quality of the nonrenewable energy, the resultant effects have not been globally attested to as viable and bold steps that can serve the transitional purpose (or perhaps beyond) before the enthronement of renewable energy regime.

Robert et al.' (2020) article entitled "The Role of Oil and Gas Companies in the Energy Transition" explored secondary data sources and maintained that the disincentive policy for the use of gas energy, adoption of a substitute technology renewable energy, decreasing of carbon emission in the economy through the reuse and recycle of materials beyond their life cycle, and investors strategic employment of renewable energy are the decarbonization strategies challenging the relevance of oil and gas fuel. Although the findings are pragmatic in approach and portray the reality of the current threat to gas energy in the global market with recommendations, such as investing in decarbonization projects, the synergy of efforts, shared resources, and knowledge seemingly required to arrive at this destination are undermined or less emphasized.

The International Renewable Energy Agency (IRENA) (2017) report, premised on secondary data, centers on how to expedite the birth of a low-carbon energy era through the renewable energy mediums. The study entitled "Renewable Energy Innovation: Accelerating Research for a Low-carbon Future" argues that nurturing innovation, decarbonizing end-use sector, integration of the power system, and taking innovation beyond $R \& D$ are the four strategic means of attaining the desirable energy transformation. Though the path set out for ending fossil fuel carbonized energy is similar to others in the literature, especially theoretical papers not reviewed in this paper, the transnational demand for the accomplishment appears unique. Nevertheless, the collaboration of stakeholders towards 
making it realizable seems underlined. Closing this gap is germane to driving a desirable future for gas fuel.

From the reviewed literature, it appears clear that more attention is given to ending nonrenewable energy with less efforts in including it as a part of the low-carbon energy mix. This is likely due to its traditional association with the highcarbon fossil fuel and the assumption of it to have attained the peak of decarbonization in the science and technology world. Besides, engaging research and technology for clean energy are rife in the literature, but how to facilitate the possibility seems not given adequate attention. Hence, this paper proceeds not only to put forward the ways to realize the aforementioned strategies in the literature but also close the gap to position gas as a potential energy source for a low-carbon mix.

\section{METHODS}

To prosecute this research, the descriptive research method was employed. Descriptive research is such that it is amenable to other types of research and describes the characteristics of phenomena and their relationship to deepen understanding (Obasi, 1999). This identified strength enables this work to explore diverse sources of data and elicit their relevance to the current state of gas energy. Also, secondary data sources are drawn from special reports, journal publications, and other credible sources. While the information was described, a textual analysis was done to appropriate its substances to the context of the study.

\section{THEORETICAL FRAMEWORK}

Dynamic capabilities theory is employed as a theoretical underpinning for this study. While the theory origin is traced to economic scholars, the influence of capacity on business strategy is associated with the work of Andrews (1971), but the contributions of Teece et al. (1997) popularize its application to strategic management (Pisano, 2015). The underlying assumption of dynamic capabilities theory is that only firms or organizations that sense and seize new opportunities by reconfiguring both the internal and external competencies to match up and respond to the environmental changes would create a sustainable market competitive advantage (cited in Cirjevskis, 2019). Put differently, entities are expected not only to be sensitive to the dynamics of their business environment but continually build up response capacity, inside and outside their operational environment, in order to possess an edge over competitors and consequently remain relevant in the industry. However, organizations and opportunities management seems idealistic because what appears as an opportunity to a firm might be mistaken for a threat by another.

Besides, Breznik and Lahovnik (2016) identified six strands of essential capacities for organization dynamism. These are managers' development of capacities, technological capacity, $\mathrm{R} \& \mathrm{D}$ capacity, innovation capacity, human resource capacity, and marketing capacity. A closer look at these capacities reveals that there is a significant interwoven relationship between or among them. For instance, while the managers develop the blueprint of general competencies development, the human resources, $\mathrm{R} \& \mathrm{D}$, technology, and innovation can hardly be undertaken in isolation because of their inherent, integrative, or combinative codependent nature. This is because the human resource occupies a central position in the occurrence of others including the marketing as well, suggesting that the extent to which an organization can be positioned for a sustainable dynamic operations in a business environment, which can either be adverse, friendly, or a highly competitive, is largely determined by the capacity of the management team. Therefore, the onus of a strategic investment in $R \& D$ of innovative technologies, $\mathrm{R} \& \mathrm{D}$, and the robust marketing to leverage on for publicity and optimum returns on investments should be sensed, conceived, and aptly seized or tactically implemented that is highly dependent on the managers.

The practical implications of dynamic capabilities theory to this research are succinct and relevant. First, the increasing opportunities of the global energy market seems to await being sensed and seized by stakeholders, especially the oil-producing countries, institutional organizations such as Organization of OilProducing Countries (OPEC) and United Nations Environment Program (UNEP), and oil-producing or servicing firms such as Shell, Agip, and Chevron. And the challenge of making it a lowcarbon emission fuel appears to make the opportunity unreal and the problem almost becoming insurmountable to them as well. Hence, the managers of these organizations that ought to develop capacities for the exploration of the business environment potentials seem to be reluctant or inertia.

Second, as a corollary to the first, instead of the managers to look both inward and outward for capacity build-up, the managers appear to have become complacent and lost their belief in the possibility of gas energy becoming a part of the low-carbon energy mix in not too distant future. As such, it suggests that the managers are either having impossibility mentality or not measure up to the task of initiating and leading a dynamic management system, implying they are bereft of the requite skill demand for a dynamic business environment.

Also, perhaps because of the competition or acceptability of the renewable energy with the fossil fuel, stakeholders as managers appear to be relegating the efficacy of research and technology in increasingly reducing the carbon content of the gas energy. Therefore, deliberate development of human resource in this direction or for this purpose looks underexploited. However, according to Pisano (2015), competing against new entrants is a part of the test of organizations' dynamic capabilities referred to as "Schumpeterian strategy." But, in this regard, the potential competencies, especially external, of the organizations are not fully engaged to bring about the emergence of transformative and novel discoveries that are capable of repositioning gas as a safe and reliable energy source among others in the market.

Consequently, new challenges are not thrown up in the science and technology world, making the strength of the dynamic management almost unexploited by operators and regulators of the energy industry as far as gas is concerned. The words of Kitenga and Thuo (2014) aptly capture it, thus "...The value of 
dynamic capabilities derives from their outputs, i.e., the creation of a new set of valuable resources. In other words, a dynamic capability that does not result in the creation of resources that allow the firm to maintain or enhance its sustainable competitive advantage would not be valuable..."

\section{REPOSITIONING GAS FOR A SUSTAINABLE ENERGY}

This section takes a new look and offers fresh perspectives on how gas can be situated among the low-carbon emission energy base. But, it should be noted that the framework of this paper is situated in the social sciences (socioeconomic and political) discourse of the subject matter and not science and technology research analysis. Nonetheless, although the journey to this lofty height has been an ongoing discourse and scientific research has not ceased as well, authors have stretched the current position further to expedite both the processes and actions basing their stance on realities rather than laboratory theories. We undertake this under three major subheadings-cutting-edge scientific research, innovative technology development, and depoliticization of low-carbon energy management.

\section{Cutting-Edge Scientific Research}

Considerable research has been done towards reducing the carbon content of fossil fuel, especially oil and gas. The quantum of investment and efforts dispensed is indicative of necessity and efforts at lessening of the carbon presence, signifying its possibility, more importantly in gas by energy scientists. For instance, carbon capturing and sequestration and utilization as decarbonization mediums, research studies are properly established in the literature by scholars such as Robert et al. (2020), Alberto (2018), and Keith (2001) among many others. However, while findings have been adapted and deployed with its attendant impacts on gas carbon decline, for example, Quadrennial Technology Review (QTR) (2015: 232) avowed that "advances made in the chemical formulations of drilling fluids have reduced their toxicity," yet it appears the trend is not progressing despite the rivalry or threat of renewable power sources pose that should have spurred intense research studies to raise the bar of new discoveries.

In addition, though the chemistry of the air and environmental pollution and greenhouse gas reduction is undertaken with technology development, the new research output of the former tends to be lesser compared to the former as observed in the literature, so that there seems to be the absence of somewhat celebrated or acknowledged breakthroughs publications or patent in this regard. Therefore, a front leap in this direction is necessary to advance the prospects of the energy industry through gas amid the bourgeoning opportunity.

Since science operates in the world of limitless possibility, one of the considered pathways to develop new experiences is engendering a "stakeholder community interest in research, development and deployment (RD\&D)." By community interest, we mean a deepening of the industry shared values and goals in the sustenance of gas fuel for not only as a transition to renewable energy but as a part of energy components of the low-carbon regime in the sector through the reconfiguration of collaborative or integrated efforts. It is worthy of note that the industry' first shared interest is her survival upon which accruing benefits to stakeholders is predicated.

Therefore, the synergy must encompass all operators or practitioners (downstream, upstream, and service) and states and transnational actors-OPEC, IEA, and UN. Partnering between the state and private firms, private firms and international organizations, or among the trio levels would raise investment on $\mathrm{RD} \& \mathrm{D}$, better motivate or mobilize researchers or research institutes to undertake groundbreaking research studies, and minimize the adverse effects of the patent on the communication of knowledge in the industry. It is interesting to note that when new findings and discoveries are easily shared or accessible, adopted, and adapted, then the better for the attainment of the decarbonization overarching objective.

While the above-articulated position is not fortuitous or likely to happen without challenges, kicks starting this via the transnational platform would lessen the likely frictions among states or the private sector either on policy, competing interests, or ethics compliance which are probable occurrences. This is because the supranational organizations' influence confers the ability to mediate and coordinate the pursuit of the industry common goals.

\section{Innovative Technology}

Technology is one of the key drivers of all sectors or industries in the present world. And the high succession of an improved version continues to pose huge challenges to both the producers and consumers. In this sense, the energy sector is not exempted in this case and therefore equally has the chance for a hi-tech development. But as some of the research findings of International Resource Panel (IRP) (2017) revelation on the implications of technology on arriving at low-carbon energy in the industry noted that technology is needed for substantial reduction in global GHG to reduce environmental impact, therefore, and to reduce pressure on land and water with their resources, there is still more space to cover in the technological advancement in the sector, especially for gas. The submission by Khan et al. (2020) revealed that there exists a negative relationship between technology and carbon emission in the case of Brazil, Russia, India, China, and South Africa (BRICS) economies that underscores the necessity for an innovative technological revolution in the industry. Hence, bracing up to meeting the challenge is needful.

Nevertheless, there is no doubt that a tremendous progress has been made in technology crafting for the improvement of gas decarbonization. For example, Fischer-Tropsch is a widely used technology in converting gas into fluids such as diesel fuel (though not in commercial scale) (Quadrennial Technology Review (QTR), 2015). Implicitly, while this established the fact that gas is convertible, it appears to be largely hinged on technology, raising the potentials for improved technical capacity for gas energy decarbonization and its adaptability and usability in the contemporary world. Therefore, accelerating the pace of an innovative technology capable of delivering unprecedented results is 
fundamental to keeping not only the sector afloat but gas fuel more amenable or relevance to its dynamics.

To pursue this objective, technological revolution campaign for the development of a more efficient and carbon reduction prone technology needs to be embarked upon by stakeholders. The paradigm shift should cut across the spectrum of the industry-extraction, drilling, refining, and end users, such as transportation, electricity, domestic, and industrial. However, both the renewable and the nonrenewable energy sources require continuous technological advancement, and there is no new development that can happen without a cost. Thus, in birthing new innovative high-technologies for a higher quality gas fuel, a two-leg revolution approach is helpful. First, a deliberate engagement of the leading and upcoming technology servicing firms in the industry by the stakeholders would suffice with the sole agenda of tasking them to take up the challenge of developing improved versions of latest pieces of equipment with clearly spelt out rewards for any attested accomplishment to the latter by the former. Moreover, just as analyzed under $\mathrm{RD} \& \mathrm{D}$, the multilateral platform should likewise be deployed for the coordination and collaboration with the private sector and its funding.

Second, the convergence of approaches in attaining cuttingedge research studies and developing innovative technologies for gas energy should be accompanied with the task of coming up with a new model of managing patent-existing and new-to forestall the likely negative impacts (such as delay in knowledge and technology sharing or transfer among stakeholders) on the recorded progress. This may require amending both the national and the international extant laws or principles to accommodate new developments in the business environment and incentivizing owners or new discovery sources with cash alongside appreciable morale-boosting rewards. Nevertheless, a scientific feasible "minimum" (though still reducible by additional efforts) carbon and methane target needs be benchmarked for each advancement or phase (supply side), or consumption spectrum (demand side) of the sector value chain for both the chemical and technological innovation to minimize incidences of a spurious or insignificant contributory claim by researchers or inventors.

\section{Depoliticization of Low-Carbon Energy Management}

The impacts of energy on the overall economy, especially in the supply of electricity to power manufacturing, households, and businesses needs alongside oil and gas for transportation, which are engines of growth, have increased states concerns about securing a steady supply aside accruing income for the source countries. Moreover, the Parish Agreement on ending carbon dioxide emission effects on global warming is also raising awareness on the importance of embracing the nonrenewable energy, posing a threat to the traditional oil, gas, and coal energy sources. However, as a part of strategies to avert energy supply disruptions, many countries-developed and developing-appear to be employing politicization of the Parish agreement, sustainable development goals, and other similar measures designed to ensure global environmental safety. Cases alluding to this practice are interrogated next.
Globally, the countries with records of high energy consumption are China, India, and the United States, perhaps due to their increasing population. But these countries, despite being signatories to the Paris Agreement and promoting renewable energy capacity, are still investing on oil, coal, and gas energy to meet up with their energy demands (Robert et al., 2020). For instance, the current American President Donald Trump' policy statement and actions tends to be reversing Barrack Obama', his predecessor, commitment to national low-carbon energy by reducing climate change funding and avowed commitment to sustain coal miners, distorting the policy and making it become partisan political issues (Roger, 2017; Selby, 2019). This appears as adversarial and dismissive strategies to decarbonization management. Similarly, Ryan (2017) avers that the Latin American countries adopted a political indifferent and lowintensity integration of climate change to national agenda strategies despite being a signatory to the Parish Agreement and instead of an accommodative strategy.

Predicated on the scholars' asseverations above, the playing of politics by some countries, especially the influential developed ones, with a commitment to the low-carbon regime is almost doubtless. But, states politicking surrounding the current move to either sustain or jettison the fossil energy with the multilateral concerns also appears to back the ploy towards its abandonment as a formal conversation on states inconsistent behaviors. Though countries desire for securing energy for economic development is legitimate, the approach or strategies employed seems inappropriate. It is interesting to note that instead of countries to be playing a double-standard stance on the global warming and related issues, striving for decarbonization of gas via investment in research and technology as a complement to the renewable energy sources would have been appreciated or applauded by other stakeholders. The EU commitment to promote renewable energy by setting up revised renewable energy directive (Ike et al., 2020) is a clear demonstration of a multilateral political will that is worthy of replication at both the national and transnational levels. In this sense, authors strongly canvass for relegation and substitution of a national or self-ambition politicization of energy security for the building of synergy efforts with other stakeholders in pursuing landmark achievements of low-carbon gas emission to circumvent its likely exclusion from being categorized among the low-carbon or future energy-mix, probably after the 2030 or extended 2050 transitional period expiration envisaged by the international community for nonrenewable fuel.

\section{CONCLUSION}

Improving the quality of gas energy in order to elongate its employment as air pollution-free, environmentally friendly, and low-carbon compliant energy is incontrovertible, hence making it more reliable. This paper submits using the multilateral platforms to coordinate pursuits of cutting-edge research studies and development and innovative technology, while states disembark on the politicization of the energy management for national economic gains would fast-track the accomplishment of 
low-carbon gas fuel and rescue its abandonment or stranding tendency. As well, the work submits that it is only when the articulated measures are applied that the management of not only the gas but other fossil fuels energy sources can be said to be poised to be accommodated in the current energy-mix in tandem with the contemporary reality of ensuring a safe and a sustainable global environment agenda.

On this premise, it is expected that opportunities in the energy market would be optimally exploited as stakeholders (mangers) and adequately respond to carrying out their role of sensing, seizing, and reconfiguring through recombination of both the internal and external resources to the global changing and to compete with renewable energy in the business environment. This would corroborate and uphold the thrust of dynamic capabilities theory and attest to the stakeholders' possession of the requisite management capacity, technological capacity, $R \& D$ capacity, innovation capacity, human resource capacity, and marketing capacity as posited by Cirjevskis (2019), Breznik and Lahovnik (2016), Pisano (2015), and Kitenga and Thuo (2014) cited in this work. Therefore, authors push for the multilateral organizations (OPEC and IEA) inclusion of special funding budgetary provision for the pursuit of cutting-edge research and the development of innovative technical

\section{REFERENCES}

Alberto, A. (2018). Natural gas dearbonization as tool for green house gases emission control. Front. Energy Res. 6, 47. doi:10.3389/fenrg.2018.00047

Bekun, F. V., Alola, A. A., and Sarkodie, S. A. (2019). Toward a sustainable environment: nexus between $\mathrm{CO}_{2}$ emission, resource rent, renewable and nonrenewable energy in 16-EU countries. Sci. Total Environ. 657, 1023-1029. 10.1016/j.scitotenv.2018.12

Breznik, N., and Lahovnik, M. (2016). Dynamic capabilities and competitive advantage: findings in case study. Management 21, 167-188.

Cirjervskis, A. (2019). The role of dynamic capabilities as drivers of business model innovation in mergers and acquisitions of technology-advanced firms. J. Open. Innov. Technol. Mark. Complex. 5 (1), 1-16. doi:10.3390/joitmc5010012

Ike, G. N., Usman, O., Alola, A. A., and Sarkodie, S. A. (2020). Environmental quality effect of income, energy prices and trade: the role of renewable energy in G-7 countries. Sci. Total Environ. 721, 137813. 10.1016/j.scitotenv.2020.137813

International Renewable Energy Agency (IRENA) (2017). Renewable energy innovation. Accelerating research for a low-carbon future. Available at: www.irena.or/-/media/ files/IRENA/agency_Accelerating_research_2017_pdf (Accessed May 22, 2020).

International Resource Panel (IRP) (2017). “A report of the InternationalResource Panel," in Green technology choices: the environmental and resource implications of low-carbon technologies. Editors Suh, S., Bergesen, J., Gibon, T. J., Hertwich, E., and Taptich, M. (Nairobi, Kenya: United Nations Environment Programme) (Accessed July 1, 2020).

Keith, D. I. (2001). "Industrial carbon management: an overview," in Carbon management: implications for R\&D in the chemical sciences and technology: a workshop report to the chemical sciences roundtable. Washington, DC: National Academies Press. Available at: ncbi.nih.gov/books/NBK44146/.

Khan, A., Muhammad, F., Chenggang, Y., Hussain, J., Bano, S., and Khan, N. A. (2020). The impression of technological innovations and natural resources inenergy-growth environment nexus: a new look into BRICS economies. Sci. Total Environ. 727, 138265. 10.1016/j.scitotenv.2020.138265

Kitenga, G. M., and Thuo, K. J. (2014). Theoretical underpinnings of dynamic capabilities. Eur. J. Bus. Soc. Sci. 3 (9), 181-190.

Muhammad, K. K., Jiang-Ziouh, T., and Muhammad, I. K. (2019). Effects of energy consumption and economic growth on carbon dioxide Emission in Pakistan with dynamic ARDL Simulation approach. Environmental Science and Pollution Research. Available at: https://doi.org/10.1007/s11356-019-05640-x capacities annually (starting with at least 25 percentage in the first five years) alongside policies, such as research funding support to any country, organization, or institution and nonmember countries inclusive, striving to actualize the dream while also taking bold steps capable of bestirring stakeholders' engagement in both the participation-policy formulation, implementation, and evaluation - and the accomplishment of a decarbonized nonrenewable energy regime. Nonetheless, scientists can undertake studies on the efficacy of new discoveries on the decarbonization progression of gas fuel.

\section{DATA AVAILABILITY STATEMENT}

The original contributions presented in the study are included in the article/Supplementary Material, further inquiries can be directed to the corresponding author/s.

\section{AUTHOR CONTRIBUTIONS}

All authors listed have made a substantial, direct, and intellectual contribution to the work and approved it for publication.

Obasi, I. N. (1999). Research methodology in political science. Enugu, Nigeria: Academic Publishing Company.

Pisano, G. P. (2015). A normative theory of dynamic capabilities: connecting strategy, know-how, and competition. Working Paper 15-036. Available at: https://www.hbs.edu/faculty/Publication\%20Files/16-036_3be51325-1fb0-421aafca-4571d958ebf9.pdf (Accessed May 22, 2020).

Quadrennial Technology Review (QTR) (2015). An assessment of energy technologies and research opportunities. Available at: www.energy.gov/sites/ prod/files/2015/09/f26/QTR2015-07fuels (Accessed July 1, 2020).

Robert, J. J., Reed, B., and Randolf, B. (2020). The role of oil and gas companies in energy transition. Available at: https://www.atlanticcouncil.org/wp-content/ uploads/2020/01/OGT-final-web-version.pdf (Accessed June 25, 2020).

Roger, R. P. J. (2017). Climate change as symbolitic politics in the United States. IIEJ Energy J. 11-15.

Ryan, D. (2017). Politics and climate change: exploring the relationship between political parties and climate issues in Latin America. Ambient. Soc. 20 (3). doi:10.1590/1809/-4422asocex007v2032017

Selby, J. (2019). The Trump presidency, climate change, and the prospect of a disorderly energy transition. Int. Stud. Rev. 45 (3), 471-490. doi:10.1017/ S0260210518000165

United Nations (UN) (2017). The sustainable development goals report. Available at: https:/unstats.un.org/sdgs/files/report/2017/thesustainabledevelopmentgoalsreport2017. pdf.

Zheng-Xia, H., Shi-Chun, X., Qin-Bin, L., and Bin, Z. (2018). Factors that influence renewable energy technological innovation in China: a dynamic Panel approach. Sustainability 10, 124. doi:10.3390/su10010124

Conflict of Interest: The authors declare that the research was conducted in the absence of any commercial or financial relationships that could be construed as a potential conflict of interest.

Copyright (c) 2021 Idowu, Joshua and Mustapa. This is an open-access article distributed under the terms of the Creative Commons Attribution License (CC BY). The use, distribution or reproduction in other forums is permitted, provided the original author(s) and the copyright owner(s) are credited and that the original publication in this journal is cited, in accordance with accepted academic practice. No use, distribution or reproduction is permitted which does not comply with these terms. 